\title{
EFFECT OF BOH ON FLOWERING OF PINEAPPLE
}

Pineapple plants may flower naturally from 10 to 15 times throughout the year, after attaining the proper age. Commercially, however, flowering is forced by the application of a calcium carbide solution $\left(\mathrm{CaC}_{2}\right)$ during the autumn. By so doing the pineapple growers are able to reduce the number of flowerings to only 3 or 4 . It is estimated that a further reduction in the number of flowerings would bring the growers still higher benefits. 
With this possibility in mind a new chemical by the name of beta-hydroxy ethyl hydrazine $(\mathrm{BOH})$ was tried at the Manati Pineapple Farm last year. It was applied to 36 pineapple plants of the Red Spanish variety at either 0.06- or 0.12-percent concentrations. About $50 \mathrm{cc}$. of the aqueous solutions were used per plant, applied to the center of the plant with a beaker. Another 36 plants received the commercial carbide treatments. In conjunction, other plots of the same variety and age under a herbicide experiment growing in the same field were similarly treated for comparison. All plants in the experiment were treated at the same time late in September.

According to the results obtained plants receiving the $\mathrm{BOH}$ application, at either concentration, had uniformly flowered by December 8 , that is, 48 days after treatments were initiated. Flowering took place in a single flush. On the other hand, none of the untreated plants, and only 40 percent of those in the herbicide experiment, flowered by the above-mentioned date. In fact, these did not reach full bloom until February 7, 1961, or about 61 days later than the $\mathrm{BOH}$-treated plants. The apparently delayed or later flowering shown by the calcium carbide-treated plants suggests that its application had been ineffective in inducing flowering in this particular case. On the other hand, the 40-percent flowering of the plants in the herbicide experiment could be attributed to the calcium carbide. The rest developed naturally and much later.

The much more advanced, uniform flowering induced by the $\mathrm{BOH}$ application had a corresponding effect upon the ripening and picking of the fruit. Almost all the fruits were harvested during February. Only a few of them were picked during the first week of March. They were of a good size, color, and quality.

Meanwhile, the delayed, irregular flowering of plants which had received the calcium carbide treatment resulted in the usual prolongued harvest period. The first fruits under this treatment were collected in early February and the last ones by the end of June. Harvesting of the crop covered a period of 5 months as compared to only 1 month for the BOH-induced crop.

In another trial $\mathrm{BOH}$ was applied to a pineapple field consisting of 1,728 six-month-old plants at the lowest concentration used in the previous experiment. The chemical was applied on December 20,1960, by means of a knapsack sprayer. After a thorough inspection of the field made February 9,1961 all the 1,728 plants were found to be in flower. However, the border plants that had been left untreated did not show signs of flower formation.

It is of significance that pineapple fields are usually grown for 18 months before calcium carbide is applied to force a flowering which then occurs 3 
or 4 months later. In our experiment much younger plants were readily and successfully forced into bloom, and this came about much more rapidly. Héctor R. Cibes

Phytopathology and Botany Department Héctor Gandía

Agronomy and Horticulture Department 